\title{
Assessment for Learning in the Calculus Classroom: A Proactive Approach to Engage Students in Active Learning
}

\author{
Reem Jaafara and Yan Lin ${ }^{a}$
}

aLaGuardia Community College, The City University of New York, USA.

\begin{abstract}
There is a variety of classroom assessment techniques we can use in the college classroom (Angelo and Cross, 1993). In an effort to diagnose and identify gaps between students' learning and classroom teaching, we implemented weekly short assessments in a calculus I classroom at an urban community college in the United States. The goals of these assessments were to identify misconceptions, and address them using an appropriate intervention. In this paper, we share these assessments, how they can be used to cement students' conceptual learning, and how it can help the instructor develop insights into students' misunderstandings. We also share students' feedback, challenges and implications for practitioners.
\end{abstract}

KEYWORDS

Assessment, calculus, community college
ARTICLE HISTORY

Received 10 September 2016 Revised 30 November 2016 Accepted11 February 2017

\section{Introduction}

There is a variety of classroom assessment techniques we can use in the college classroom (Angelo and Cross, 1993). In the mathematics classroom, graded quizzes and midterm tests are the most common forms of assessments. In an effort to diagnose and identify gaps between students' learning and classroom teaching, we implemented weekly short assessments in a calculus I classroom at an urban community college in the United States. Calculus I is the first math class where students encounter proofs and theorems and is a gateway

\section{CORRESPONDENCE Reem Jaafar $\square$ rjaafar@lagcc.cuny.edu}

(c) 2017 Reem Jaafar \& Yan Lin.

Open Access terms of the Creative Commons Attribution 4.0 International License apply. The license permits unrestricted use, distribution, and reproduction in any medium, on the condition that users give exact credit to the original author(s) and the source, provide a link to the Creative Commons license, and indicate if they made any changes. (http://creativecommons.org/licenses/by/4.0/) 
to those who are in pursuit of Science, Technology, Engineering, and Math (STEM) majors (Cullinane, 2011).

Community Colleges serve a diverse, non-traditional body of students. Nationwide, a majority of students entering community colleges are referred to one or more courses in remedial mathematics (Bailey, Jeong, \& Cho, 2010). Among these students, few of them make it to calculus I. With this challenge, we believe that having a diagnostic test involving the pre-requisite concepts is essential for both teachers and students to understand the challenges ahead. During the course, periodic assessments are important for students to reflect on their learning, and for the instructor to work on proper interventions. Therefore, the assessments were not all graded, but were corrected. The goals of these assessments were to 1) immediately identify misconceptions, and 2) address the misconceptions using an appropriate intervention. The intervention took place in class in the form of discussions related to the assessments, in addition to guided summaries.

In guiding our research, we used some principles listed in Measuring What Counts: A Conceptual Guide for Mathematics Assessment (National Research Council \& Bass, 1993). These principles included: 1) "Assessment should reflect the mathematics that is most important for students to learn", 2) "Rather than forcing mathematics to fit assessment, assessment must be tailored to the mathematics that is important to learn", and 3) "Assessment should enhance mathematics learning and support good instructional practice" (National Research Council \& Bass, 1993, p. 14).

This paper focuses on the benefits of frequent and short assessments, its benefits to students' conceptual learning and how it can help the instructor develop insights into students' misunderstandings. After administering the assessment, an intervention aims to remediate these misconceptions. We attempt to answer two important questions: i) To what extent are assessments beneficial to students' learning, and ii) Can the intervention improve students' learning? We also share students' feedback, challenges and implications for practitioners.

\section{Literature Review}

\section{Assessment, Active Learning, and Feedback}

Classroom assessment is not unique to K-12 but is needed in the college classroom (Angelo \& Cross, 1993). There is a plethora of techniques for faculty to choose from. For instance, one technique is pre-assessment (or background knowledge), which is used as a means to determine the starting point for a given lesson (Angelo \& Cross, 1993, p. 121). Misconception/preconception checks are meant to correct incomplete or erroneous knowledge so one can eliminate obstacles that may impede students' conceptual understanding. Guided summaries are similar to empty outlines (p.138) - they encourage students to pay more attention to the details. The "muddiest point" is equivalent to the most common struggles/misconceptions. It consists of asking students the most difficult/challenging questions about a particular topic. Following the assessment, the intervention consists of classroom discussions, based on the results of the given assessments. During 
these discussions, students are redirected to correct their mistakes and to review a peer's solution. They are designed to promote active learning and to push students to identify and correct their own misconceptions. This procedure is intended to enhance "their performance by critiquing their solution" (Bean, 2011, p 149). The active learning approach is embodied in the collaborative aspect of the intervention, to create excitement, and to provide the opportunity for students to teach and critique each other (Bonwell \& Eison, 1991). These student-centered activities promote inquiry and knowledge acquisition. Active learning is particularly important with nontraditional and a culturally diverse student body (Meyers \& Jones, 1993, p. 11). Active learning may not always involve interaction with a peer, it may instead involve reflection and selfmonitoring of both the processes and the results of learning (Cross, 2003, p.5).

In terms of assessment, studies have shown that students still prefer traditional forms of testing as assessment (Iannone \& Simpson, 2015). It has been shown that active learning can improve students' performance on psychology tests (Yoder \& Hochevar, 2005). The use of active learning techniques is "vital because of their powerful impact upon students' learning" (Bonwell \& Eison, 1991, p. 5).

\section{Calculus I: A Global Perspective}

Across different countries, mathematics educators have invested in

redesigning classroom instruction of calculus as an acknowledgement of the importance of the subject. There is a worldwide consensus that the subject is difficult for students (Robert \& Speer, 2001). High school students in Bhutan used graphing activities based on the learning cycle approach to establish the relationship between differentiation and integration (Kinley, 2016). In Sweden, a team of researchers from Finland carried out an experiment at a Swedish University to understand critical aspects of the definite integral concept, and whether technology-assisted teaching can improve students' understanding of the concept (Attorps, Björk, Radic, \& Tossavainen, 2013).

In examining the discourse on the limit concept, Güçler (2013)

highlighted the conceptual challenges of the topic by examining the discrepancies between the instructor's discourse and the students' discourse. Idris (2009) used writing to move students away from instrumental understanding, and more towards relational and logical understanding. Most of the rules learned from instrumental understanding are short-lived. Often students see themselves applying rules without knowing why the rule works. Writing was also used in other research studies as a vehicle for assessment (Idris, 2009; Jaafar, 2016; Pugalee, 2001).

It is also important for students to detail the relationship between conceptual and procedural knowledge in order to understand the subject, as these two facets are "mutually supportive" of mathematical understanding (Scheja \& Pettersson, 2009). Through interviews with students who just finished a calculus course, Scheja and Pettersson (2009) found that their initial understanding of this course was algorithmic. Some researchers used concept maps and interpretative essays as a form of assessment (Bolte, 1999). Studies further point to the importance of conceptual understanding: Rybolt and Recck (2012) showed that students who were asked to use the conceptual method performed better than the ones who were provided only with the formulas, which was referred to as computational convenience. Another study showed that 
as long as students focused on the learning of concepts, they would achieve the same level of conceptual and procedural understanding. Therefore, we adapted the use of assessments to engage students' conceptual learning (Porter \& Masingila, 2000).

Students are also expected to have a mastery of algebraic operations. As

Dawkins and Epperson's (2014) study indicated, students who lacked proficiency in reasoning in the algebraic and graphical registers would be underprepared for a calculus course; in their research, most students including the top-performing students heavily depended on the algebraic method; and students who excelled in the course were the ones who had the good study habit of learning both conceptually and procedurally (Dawkins \& Epperson, 2014).

\section{Data Collection}

\section{Sample}

The sample for the study consisted of two sections of Calculus I classes, section A and section B. Both sections were taught by the same instructor. In section A, 21 students completed the course, and in section B, 25 students completed the course. There were differences between the students enrolled in these two sections. Section A did not have any student repeating the course, and only one student was previously placed in a remedial math course. The mean G.P.A of students at the beginning of the semester was 3.57. The background of students in Section B was different: $15 \%$ of students had repeated the same course, and $25 \%$ of the students had a remedial math course before. The mean G.P.A of students at the beginning of the semester was 3.38 .

\section{Pre-Test}

After obtaining the approval of the Institution's Review Board, a survey was administered at the beginning of the semester to assess students' conceptual knowledge. They were asked to explain what the following concepts meant to them: function, domain, range, the slope of a line, the tangent line to a curve, velocity, horizontal asymptote and vertical asymptote. These were openended questions. Students were graded on a scale of 1 to 4 , where 1 represented no idea, 2 represented hint, 3 represented some knowledge, and 4 represented complete understanding. The results showed that students lacked the conceptual background. Maharaj and Wagh (2014) outlined the importance of pre-course diagnostics for students embarking on a calculus course: they found that the pre-course diagnostics exposed students to their own work habits and raised awareness to the lack of basic background knowledge. They underlined the importance for students to understand the expected learning outcomes. 
Table 1

Pre-Test Results: Sections A \& B combined.

\begin{tabular}{lcccc}
\hline \multicolumn{1}{c}{ Concept } & $\begin{array}{c}\text { Scale of 1: no } \\
\text { idea }\end{array}$ & $\begin{array}{c}\text { Scale of 2: } \\
\text { Hint }\end{array}$ & $\begin{array}{c}\text { Scale of 3: } \\
\text { some accurate } \\
\text { knowledge }\end{array}$ & $\begin{array}{c}\text { Scale of 4: } \\
\text { understand }\end{array}$ \\
\hline Tangent line & $74 \%$ & $3 \%$ & $5 \%$ & $18 \%$ \\
$\begin{array}{l}\text { Vertical } \\
\text { Asymptote }\end{array}$ & $79 \%$ & $15 \%$ & $3 \%$ & $3 \%$ \\
$\begin{array}{l}\text { Horizontal } \\
\text { Asymptote }\end{array}$ & $87 \%$ & $10 \%$ & $0 \%$ & $3 \%$ \\
Range & $43 \%$ & $31 \%$ & $18 \%$ & $8 \%$ \\
Velocity & $67 \%$ & $20 \%$ & $13 \%$ & $0 \%$ \\
Function & $44 \%$ & $46 \%$ & $5 \%$ & $5 \%$ \\
Domain & $41 \%$ & $36 \%$ & $15 \%$ & $8 \%$ \\
Slope of a line & $36 \%$ & $41 \%$ & $3 \%$ & $20 \%$ \\
\hline
\end{tabular}

The pre-test provided a picture of students' starting point: $38 \%$ confused the concept of the tangent line with the trigonometric function, $\tan (\mathrm{x})$. This mistake is common among calculus students (Vincent, LaRue, Sealey, \& Engelke, 2015). Most students attempted to answer the question about horizontal asymptotes by drawing graphs either related to the answer or that were completely unrelated. The student who had a hint simply drew a function with a horizontal line saying "as x gets large". One startling answer was, "where the function takes a break". The same pattern of answers was given for the vertical asymptotes. Most students left the question related to the velocity blank. The pre-test showed students' lack of conceptual understanding. Students at community colleges often study calculus after taking a developmental math course, college algebra and pre-calculus, where the focus is mainly on addressing weak computational skills. It turned out that the majority of students were not able to master the basic concepts, such as the definition of a function, domain, and the slope of a line. One student for instance, responded that a function is " $4 \mathrm{x}+2=6$, solve for $\mathrm{x}$ or something"; another student stated, "function works as 
machine that helps to find out the statistics of anything, symbol is $f: f(x)=b x+e$ (linear function)".

The pre-test served as check on students' background. Most of the assessments were not related to the pre-test. However, students' lack of conceptual understanding motivated the instructor to include conceptual questions throughout the semester.

\section{Assessments of Concepts}

Every week, students took one assessment. We share the results of the assessments of topics in differential calculus.

\section{Tangent Line}

The first concept in differential calculus is the slope of the tangent.

Therefore, it was urgent to address the misconceptions surrounding it from the very beginning. After covering the chapter in class, students were given a short assessment (assessment1 in table 2), to which 6\% and 14\% answered correctly in sections A and B, respectively. After returning the assessment to the students, students discussed their answers with a peer, followed by a general discussion. They were subsequently asked to provide a correction to their responses. During the next class meeting, a post-assessment (assessment 2) was administered. A substantial improvement was seen in each section $(43 \%$, and $36 \%$, respectively). Although students in section A had a lower starting point (see pre-test results in table 1), they eventually outperformed students in section B.

One major issue after assessment 2, was students' inability to move away from the "distance over time" formula and how to transition from average to instantaneous velocity. Students still struggled to apply the concept of the slope of the tangent line. Others were able to connect the concepts as demonstrated by the following response: "the concept of the tangent of velocity is related in a sense because the slope (of the tangent) of a curve is a rate. And at the tangents you can say that instantaneous velocity occurs. Finding the tangent, you would find the instantaneous velocity of an item in motion at a certain point in time."

Table 2

Tangent Line Assessment

\begin{tabular}{|c|c|c|}
\hline $\begin{array}{l}\text { Assessments in } \\
\text { Chronological Order }\end{array}$ & Question & $\begin{array}{l}\text { Percentage of students Who } \\
\text { understood the concept } \\
\text { (Section A, Section B) }\end{array}$ \\
\hline
\end{tabular}

Assessment 1

Explain the

$6 \%, 14 \%$

relationship between

slope of the tangent

and velocity 


\section{Limit}

Limits are a central topic. There are conceptual challenges to the teaching of limit (Güçler, 2013). Students were often asked to discuss the existence of limits, write about it using equations, and explain it using "everyday" language.

The first assessment (table 3) indicated that students still did not grasp the difference between limit and the value of the function at a point. This was demonstrated in examples with a removable discontinuity. The language used by some students was not accurate, even though their explanation showed some understanding of the concept. These examples demonstrated students' struggles when using correct mathematical notation and are illustrated by sample responses such as "If $\lim _{x \rightarrow a^{-}}$and $\lim _{x \rightarrow a^{+}}$are equal". This phenomenon points to students' tendency to ignore the relevance of mathematical language (Thompson, 1994). Other responses stated, "the limit exists when the function going on the left and going on the right is are equal". Another response showed students' struggles when trying to explain the limit and the value of a function at a point: "When the point on the function, it doesn't have another "y" value on the function, it only has a value at a that exists." The intervention consisted of collecting a sample of students' mistakes and have all students in class critique and reformulate them using accurate mathematical language. The samples consisted of both conceptual errors and statements with inaccurate notations as illustrated in the two examples above. Assessment 2 showed improvement: students were able to explain the difference between limits and value of a function at a particular value of $\mathrm{x}$. Some illustrated with graphs, others by defining functions. As in the previous assessment, the improvement in students' understanding in section A was higher than that of section B.

Table 3

Limit Assessment

\begin{tabular}{|c|c|c|}
\hline $\begin{array}{l}\text { Assessments in } \\
\text { Chronological Order }\end{array}$ & Question & $\begin{array}{l}\text { Percentage of students Who } \\
\text { understood the concept } \\
\text { (Section A, Section B) }\end{array}$ \\
\hline
\end{tabular}

Assessment $1 \quad$ Write the condition for $33 \%, 30 \%$ which the limit of a function at the point a exists. Illustrate with a sketch. 


$$
\begin{gathered}
\text { If } f(x) \text { is undefined at } \\
x=1 \text {, does it mean that } \\
\lim _{x \rightarrow a} f(x) \text { exist? }
\end{gathered}
$$

$80 \%, 64 \%$

\section{Chain Rule}

Chain rule is a topic that represents a procedural challenge for students, especially when combined with other differentiation rules such as the product and quotient rules. Assessment 1- although may seem simple - showed students' confusion when they needed to use more than one rule to obtain the derivative (chain rule combined with the product rule). Some attempted to use the chain rule before the product rule, or ignoring the product rule altogether, as demonstrated in answers such as " $x .2 \sin x^{2}$ ". Another source of error came from differentiating $\cos x^{2}$. The error was the result of students' inability to identify the outer function from the inner function, illustrated by stating that the derivative of $\cos x^{2}$ is " $2 \sin x \cos x$ ".

Students were subsequently asked to find derivatives using the chain rule step-by-step by first labelling the outer and the inner function, then by providing a detailed step-step explanation of the steps. Students in section A continuously improved their performance on this task (table 4), even as the questions became more challenging. Having students explain the steps confirmed their conceptual understanding of the chain rule.

In section B, students showed improvement between assessments 1 and 2, but did not show the same improvement with implicit differentiation (assessment 3); some challenges came from handling long algebraic expressions. This is consistent with other assessments where improvement in students' performance in section A was more pronounced.

Table 4

Chain Rule Assessment

\begin{tabular}{ccc}
\hline $\begin{array}{c}\text { Assessments in } \\
\text { Chronological Order }\end{array}$ & $\begin{array}{c}\text { Question: Find } y^{\prime} \text { the } \\
\text { derivative of the function. } \\
\text { State the Rule used. }\end{array}$ & $\begin{array}{c}\text { Percentage of students Who } \\
\text { understood the concept } \\
\text { (Section A, Section B) }\end{array}$ \\
\hline Assessment 1 & $y=x \cos \left(x^{2}\right)$ & $32 \%, 15 \%$ \\
Assessment 2 & $y=\ln \left(\cos \left(x^{4}\right)\right)+e^{4 x \sin (2 x)}$ & $52 \%, 60 \%$ \\
Assessment 3 & $\sin (x+y)=2 x-2 y$ & $71 \%, 48 \%$
\end{tabular}

\section{Local vs Absolute Extrema}


Another concept where students had a good intuitive idea but may have lacked the mathematical rigor in expressing their thoughts, was local versus absolute extrema. When students were asked about the difference between the absolute and local minimum, they resorted to explanations such as "The absolute minimum is the smallest number in its domain", "local minimum is the place where the slope of the graph is zero, whereas the absolute minimum is the lower zero slope on the graph." Other responses revolved around their location: "An absolute min can have an end point but a local min doesn't/can't have an end point". These expressions reiterated students' struggles with mathematical language. Students were asked to examine the textbook definition, underline keywords and compare it with their own statement. They had to detail why their definition may be inaccurate or incomplete. The following assessment probed students into higher-order thinking by not just providing the definition, but by applying the actual definition. The second assessment showed improvement in both sections (table 5). An improved response from one of the students - whose previous explanation was quoted above - was "Absolute minimum is the smallest value in the domain. Local minimum has a smaller value than other points around it."

Table 5

Local and Absolute Extrema Assessment

\begin{tabular}{|c|c|c|}
\hline $\begin{array}{l}\text { Assessments in } \\
\text { Chronological Order }\end{array}$ & Question & $\begin{array}{l}\text { Percentage of students Who } \\
\text { understood the concept } \\
\text { (Section A, Section B) }\end{array}$ \\
\hline
\end{tabular}

Assessment 1

Assessment 2

$$
\begin{gathered}
\text { Explain the difference } \\
\text { between an absolute } \\
\text { minimum and a local } \\
\text { minimum. }
\end{gathered}
$$

Graph a function that has an absolute maximum but

no local maximum, and

explain the difference

between the two.
$25 \%, 10 \%$

$52 \%, 40 \%$

\section{Difference Between Continuity at a Point Versus Continuity on an Interval}

Continuity at a point is better understood than continuity on an interval. It is startling how students could not translate their understanding of the continuity at a point to their understanding of the continuity on an interval. In the initial assessment about continuity at a point, some students confused the 
condition for continuity with the condition of the existence of the limit. Following assessment 1 (table 6), students were asked to compare the definition of the existence of the limit and that of continuity at a point, to better understand both definitions and to draw the relationship between them. They were also given a short problem that illustrated different cases of discontinuity at a point and the existence of the limit for each case illustrated.

Continuity across an interval remained a challenge with less than $40 \%$ of students in each section mastering the concept by the end of the course. When asked about it in assessment 1, students resorted to the explanation such as "this is the case of a polynomial function" missing on the theorem that states that all functions are continuous in their domain. Other explanations included "it is continuous if the function is defined at every point in the interval". One student struggled with mathematical language: "the line stops at a point before $[a, b]$. It continue at point $[a, b]$, included point a and b." The intervention consisted of working on examples that contradicted the statement made: "Draw a function that is discontinuous on [-4,4], but that is defined for all $\mathrm{x}$ in $[-4,4]$." This should take students back to the definition of the existence of the limit.

Table 6

Continuity at a point and continuity in an interval Assessment

\begin{tabular}{|c|c|c|}
\hline $\begin{array}{l}\text { Assessments in } \\
\text { Chronological Order }\end{array}$ & Question & $\begin{array}{l}\text { ercentage of students Who } \\
\text { understood the concept } \\
\text { (Section A, Section B) }\end{array}$ \\
\hline $\begin{array}{l}\text { Assessment } 1 \text {. Continuity } \\
\text { at a point at a point. }\end{array}$ & $\begin{array}{l}\text { What does it mean for } \mathrm{f} \text { to } \\
\text { be continuous at a point a? }\end{array}$ & $65 \%, 32 \%$ \\
\hline $\begin{array}{l}\text { Assessment } 2 \text {. Continuity } \\
\text { at a point at a point. }\end{array}$ & $\begin{array}{c}\text { Write an equation } \\
\text { expressing the fact that a } \\
\text { function } \mathrm{f} \text { is continuous at } \\
3 .\end{array}$ & $86 \%, 88 \%$ \\
\hline $\begin{array}{l}\text { Assessment } 1 \text {. Continuity } \\
\text { in an interval }\end{array}$ & $\begin{array}{l}\text { What does it mean for } f \text { to } \\
\text { be continuous on the } \\
\text { interval }(-\infty, \infty) \text { ? What can } \\
\text { you say about the graph of } \\
\text { such a function? }\end{array}$ & $29 \%, 25 \%$ \\
\hline $\begin{array}{l}\text { Assessment 2. Continuity } \\
\text { in an interval }\end{array}$ & $\begin{array}{c}\text { What does it mean for } \mathrm{f} \text { to } \\
\text { be continuous on the } \\
\text { interval }[\mathrm{a}, \mathrm{b}] ?\end{array}$ & $38 \%, 28 \%$ \\
\hline
\end{tabular}




\section{L'Hospital Rule}

Although L'Hospital's rule seems to be a facilitating tool for calculating limits, students were often stuck on the rule when applied to indeterminate powers, so we focused the intervention on that particular case of L'Hospital rule. In the intervention, students were asked to detail the steps used in each case and to explain the different cases where L'Hospital rule may apply. In the follow-up assessment, students in section A showed substantial improvement in applying L'Hospital rule to an indeterminate power, but students in section B regressed. The second assessment was part of the final exam, so the instructor could not design a proper intervention. In section B, $48 \%$ of students started by finding the limit of the logarithm, but half of them made a mistake in taking the derivative of $\ln (1-2 x)$, impeding their ability to complete the question. Thus, only $24 \%$ completed the question correctly.

Table 7

L'Hospital Rule Assessment

\begin{tabular}{ccc}
\hline $\begin{array}{c}\text { Assessments in } \\
\text { Chronological Order }\end{array}$ & Question & $\begin{array}{c}\text { Percentage of students Who } \\
\text { understood the concept } \\
\text { (Section A, Section B) }\end{array}$ \\
\hline $\begin{array}{c}\text { Assessment 1: Apply } \\
\text { L'Hospital Rule to an } \\
\text { indeterminate power }\end{array}$ & Calculate $\lim _{x \rightarrow 1^{+}} x^{\frac{1}{1-x}}$ & $33 \%, 48 \%$ \\
Assessment 2. Apply & Calculatelim \\
$\begin{array}{c}\text { L'Hospital Rule to an } \\
\text { indeterminate power }\end{array}$ & $2 x)^{\frac{1}{x}}$ & $95 \%, 24 \%$ \\
\end{tabular}

\section{Interviews}

At the end of semester, interviews were solicited by the research assistant, according to the protocol detailed in the Institutional Review Board application. Five students responded. The interviews took place about a month after the completion of the course. The goal was to understand students' retention of information. The first part of the interview consisted of asking students to briefly explain nine concepts; the second part of the interview was the exchange part to solicit explanations to selected questions. Some questions during the second part directed students to detail the most challenging concepts. The interviews were conducted by both the professor and the research assistant.

The topics included: slope of the tangent, the existence of the limit, continuity, maximum and minimum of functions, horizontal asymptote and vertical asymptote. Four of the five students stated that graphing a function using different information (e.g. limits and derivatives) was the most challenging aspect of the course. One student mentioned L'Hospital rule when 
applied to indeterminate power. We detail the responses of students by topic. The students interviewed represented a diverse sample with different achievement levels.

\section{Slope of The Tangent}

Students' understanding of the concept of the slope of the tangent was a little disappointing. Students' explanation focused on using the slope of the line, rather than the tangent and did not use calculus language until pressed by the interviewers. For instance, student 1 used " $y=m x+b$ " and stated that the slope is either positive or negative. When asked whether there could be another way to define it using calculus concept, the student recalled the use of derivatives.

The second student did not remember the definition of the slope of the line. He/She forgot about the basics, not knowing the difference between a positive and a negative slope until pressed further by the interviewers. The student did not recall the relation of the concept to derivatives.

The third and fourth students defined the slope of the secant instead, using " $\mathrm{y}-\mathrm{y}_{1}=\mathrm{m}\left(\mathrm{x}-\mathrm{x}_{1}\right)$ ", the students were able to differentiate between positive and negative slope but did not transition to define the slope of the tangent from the secant until probed by the interviewers.

Finally, one student did not recall any information about the slope of the tangent and left it blank. When pressed, the student provided " $y=m x+b$ " as an answer.

None of the five students used the definition of the derivative at a point using the limit. Students' lack of retention of the most fundamental concept of Calculus I is eye-opening, and poses relevant questions to practitioners in the field: students tend to forget the fundamental difference between the slope of the secant and the slope of the tangent. The course is structured in such a way that it opens with the concept of the slope of the tangent and ends with the Fundamental Theorem of Calculus relating the two branches of calculus. This presents an opportunity for instructors teaching the course in rethinking how to end the course in a way that relates the two branches of Calculus more effectively. Kinley (2016) suggested graphing activities to better help students understand the relationship between integral and differential calculus, and thus can be used to remind students about the definition of the slope of the tangent.

\section{The Existence of the Limit}

In this question, students were asked to show an example explaining how to find "The Limit of a function as x approaches 2", for a function of their choice. The first student drew a discontinuous function and answered with the correct notation. The second illustrated different cases and used proper notations. The third student confused the limit with the definition of continuity at $\mathrm{x}=2$. When the student was pressed further during the discussion, he/she realized the mistake and was able to correct it. Finally, the last two students were able to provide examples of function and calculate the limit as x approached 2 correctly, and illustrated with a sketch.

\section{Continuity}

This question was open-ended and asked students to explain what it means for a function to be discontinuous at a point. The first student drew a discontinuous function and stated that "not all the points on the graph exist. Holes can be seen in the graph".

When probed further, the student stated, "holes mean gaps". When told that the definition is not accurate and that we needed a mathematical definition 
using the limit, the student was able to provide an accurate definition. The second student stated, "the limit must exist", but was probed further in order to relate it to the value of the function at the specific point. The third student only provided a graph of a continuous function, but did not provide a mathematical definition or explanation. The fourth showed a discontinuous function at a point and stated, that at that point "the value of the function is not equal to the value the limit". Finally, the last student drew a curve with a gap, but missing the $\mathrm{x}$ and y axes, and correctly explained why the function is not continuous using the definition.

\section{Maximum of a Function}

Student 1 drew a graph, and wrote "the highest point of the function". Student 2 graphically explained that the maximum is where the first derivative is 0 . Student 3 understood the question but was negligent in providing an accurate definition using $\mathrm{y}$ or $\mathrm{f}(\mathrm{x})$ but resorted to saying, "the highest value of $\mathrm{x}$ ", while student 4 first related the maximum to the second derivative test but when pressed harder, the student related it to the first derivative test. The student correctly drew the function. Finally, student 5 graphically interpreted it pointing to the maximum on the graph but did not connect it to the derivative until pressed.

\section{Horizontal Asymptotes}

Student 1 drew the function correctly, as well as the asymptote. After pressing, the student used the definition of limit to justify asymptote. Student 2 confused horizontal with vertical. The third student used limits and a graph to define horizontal asymptotes. The fourth student correctly explained the asymptote as a limit but used inaccurate notation " $\lim _{x \rightarrow \infty} f(x)=$ some \#". Finally, the last student drew a graph only.

\section{Vertical Asymptotes}

Students' understanding of vertical asymptote almost reflected their understanding of horizontal asymptotes. Student 1 drew the function correctly, as well as the asymptote, without using limits. Student 2 confused vertical asymptote with horizontal asymptote. The third student used limits and a graph to define vertical asymptotes. The fourth student correctly explained the asymptote as a limit but used the inaccurate notation $\lim _{x \rightarrow \text { some\# }} f(x)=\infty "$. Finally, the last student drew a graph only.

\section{Students' Surveys}

An end-of-semester survey was conducted for collecting feedback of students' learning experience in this class. Students could choose more than one answer. Figure 1 shows what students found was the most challenging aspect of the course. Students were challenged by different elements including applying theories or concepts to new problems (46\%), finishing homework (37\%) and difficulty in reading and understanding the textbook (27\%). 


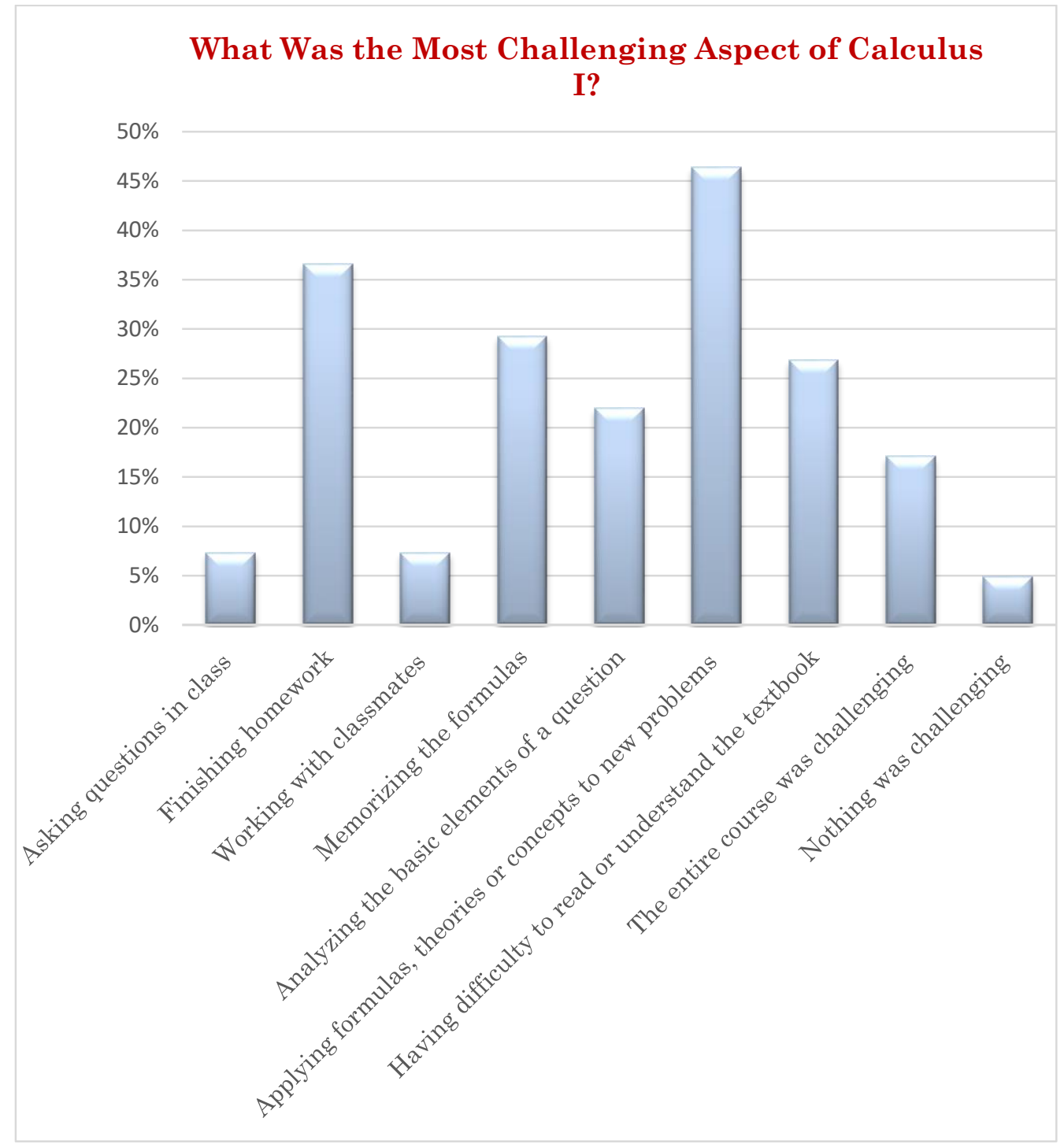

Figure 1. Students' responses to the most challenging aspect of the course.

When asked about the assessments, $71 \%$ agreed that reading the textbook could help them do better on the assessments. Seventy-three percent of students felt that the assessments were somewhat difficult, $20 \%$ thought they were "very difficult", and only $7 \%$ felt that they were not difficult at all. However, the majority of students $(60 \%)$ felt that the assessments were helpful because they helped them realize what they didn't understand, and helped them prepare for the test. Figure 2 shows how students ranked concepts by level of difficulty. Students found that curve sketching and optimization problems to be more difficult than other topics. This feeling was echoed in the interviews. Curve sketching presented challenges to students where students needed to apply several concepts concurrently to be able to sketch (e.g. increasing, decreasing tests, first derivative tests, asymptotes). 


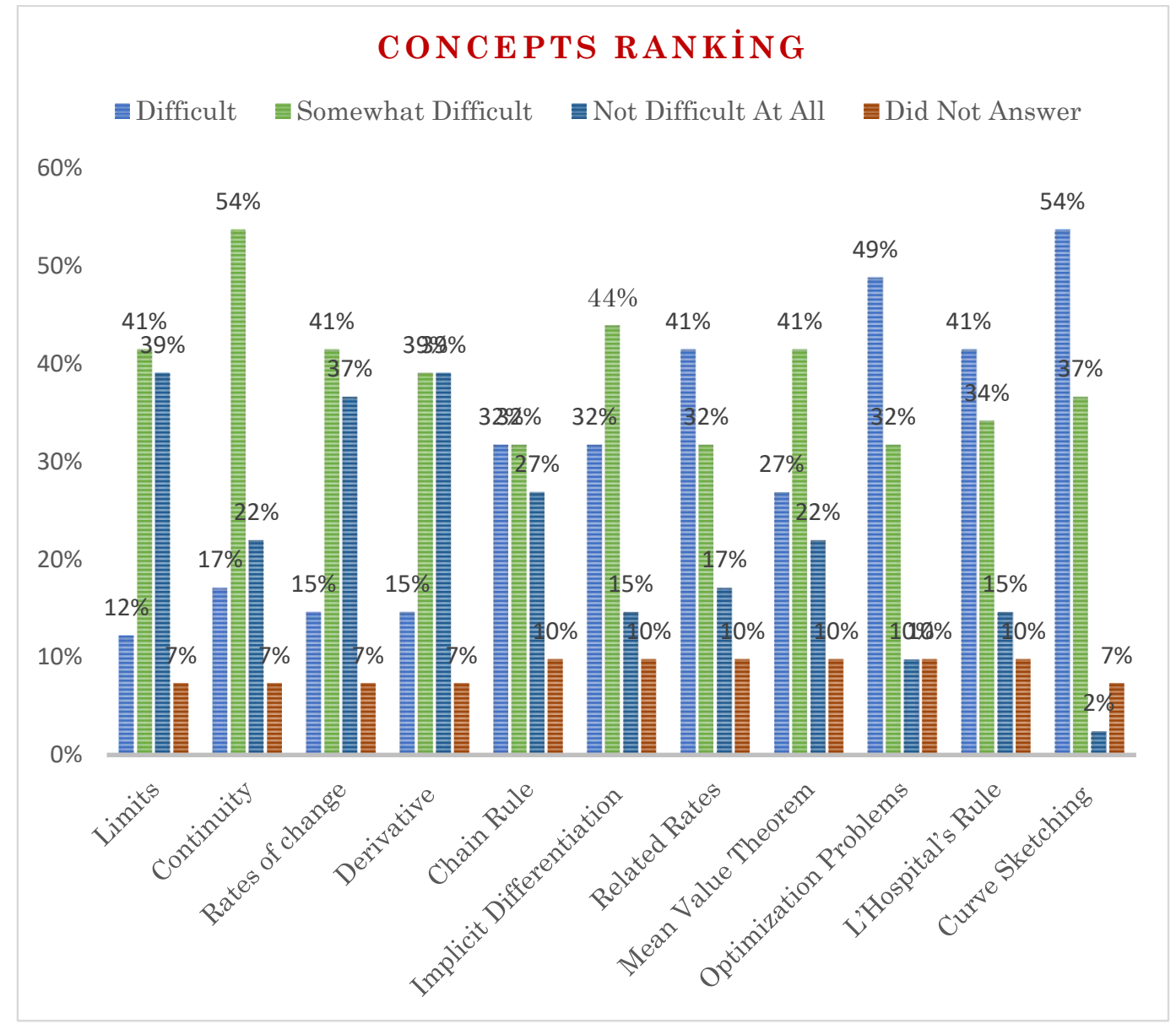

Figure 2. Ranking of concepts by level of difficulty.

When asked about the difference between calculus and the pre-requisite course pre-calculus, $41 \%$ of students stated that calculus was much harder than pre-calculus, and $37 \%$ thought that the course was "slightly" harder than precalculus. However, the majority of students $(90 \%)$ stated that they felt prepared to take calculus II.

\section{Discussion and Conclusion}

Although the sample size was small, the ideas presented in this paper may be relevant to all instructors teaching a calculus course for a nontraditional student body. Short and brief assessments can be useful in highlighting misunderstandings so the instructor may choose a proper intervention. To promote active learning, the intervention focused on studentcentered discussions. Students were directed to correct and critique their own mistakes. Our guiding principle was based on the fact that assessments were tailored to the mathematics that is important for students to learn, and our ultimate goal was to enhance calculus learning while providing good instructional practices (National Research Council \& Bass, 1993). Indeed, we noticed a substantial improvement in students' understanding in assessment 2. 
The assessments can also provide insights on the most challenging concepts so a proactive approach can be taken when teaching these concepts. In several chapters, we noticed a confusion between concepts such as the difference between continuity at a point and continuity on an interval, the definition of continuity at a point and that of the existence of the limit, application of the chain rule, L'Hospital rule when applied to indeterminate exponent, and the meaning of the slope of the tangent.

The study was also eye-opening in acknowledging that there was no "one size fits all" solution. The intervention did not show equal results in sections A and B. As described earlier, a quarter of the class in section B started from remedial mathematics and $15 \%$ of the students had repeated the same course. Therefore, it is essential to get students' profiles at the beginning of the semester so the instructor understands better students' potential weaknesses. Students who were originally placed in a remedial mathematics course tended to make more algebraic mistakes than those who were not. Explaining mathematical reasoning using accurate language was also a challenge to most of the students.

Andrew Wiles, a well-known British mathematician, said "The definition of a good mathematical problem is the mathematics it generates rather than the problem itself." Similarly, we should communicate to students that the excitement in learning calculus and solving problems is not solely about fulfilling requirements, but is about learning how to express their mathematical ideas accurately.

\section{Disclosure statement}

No potential conflict of interest was reported by the authors.

\section{Notes on contributors}

Reem Jaafar, Ph.D. Associate Professor of Mathematics, Engineering and Computer Science at LaGuardia Community College, City University of New York. CoDirector of Supplemental Instruction Program.

Yan Lin, B.S. Research Assistant, and Student Success mentor. LaGuardia Community College, City University of New York

\section{Acknowledgment}

This research project is supported by a 2016-2017 Professional Development Grant administered by the Educational Development Initiative Team (EDIT) of LaGuardia Community College.

The authors would also like to acknowledge the generous support of Dr. Bret Eynon, Associate Provost and Assistant Vice President for Academic Affairs.

\section{References}

Angelo, T. A., \& Cross, K. P. (1993). Classroom Assessment Techniques: A Handbook for College Teachers.Second Edition (2nd ed.). San Fransisco, CA: Jossey-Bass.

Attorps, I., Björk, K., Radic, M., \& Tossavainen, T. (2013). Varied Ways to Teach the Definite Integral Concept. SOURCE International Electronic Journal of Mathematics Education, 8(23), 81-99. 
Bailey, T., Jeong, D. W., \& Cho, S. (2010). Referral, enrollment, and completion in developmental education sequences in community colleges. Economics of Education Review, 29(2), 255-270. doi:10.1016/j.econedurev.2009.09.002

Bean, J. C. (2011). Engaging ideas: The professor's guide to integrating writing, critical thinking, and active learning in the classroom. San Francisco: Jossey-Bass.

Bonwell, C. C., \&Eison, J. A. (1991). Active learning: Creating excitement in the classroom. ASHEEric Higher Education Report No. 1. Washington, DC.: George Washington University.

Bolte, L. A. (1999). Using Concept Maps and Interpretive Essays for Assessment in Mathematics. School Science and Mathematics, 99(1), 19-30. doi:10.1111/j.1949-8594.1999.tb17442.x

Cross, K. P. (2003). Techniques for Promoting Active Learning. League for Innovation in the Community College Educational Testing Service, AZ: The Cross Papers \#7.

Cullinane, M. J. (2011). Helping Mathematics Students Survive the Post-Calculus Transition. PRIMUS, 21(8), 669-684. doi:10.1080/10511971003692830

Dawkins, P. C., \& Epperson, J. A. (2014). The development and nature of problem-solving among first-semester calculus students. International Journal of Mathematical Education in Science and Technology, 45(6), 839-862. doi:10.1080/0020739x.2014.884645

Güçler, B. (2013). Examining the discourse on the limit concept in a beginning-level calculus classroom. Educational Studies in Mathematics (2013), 82, 439-453.

Idris, N. 2009. Enhancing Students' Understanding in Calculus Through Writing. International Electronic Journal of Mathematics Education. 4(1): 36-55.

Iannone, P., \& Simpson, A. (2015). Students' preferences in undergraduate mathematics assessment. Studies in Higher Education, 40(6), 1046-1067. Retrieved from http://dx.doi.org/10.1080/03075079.2013.858683

Jaafar, R. (2016). Writing-to-Learn Activities to Provoke Deeper Learning in Calculus. PRIMUS, 26(1), 67-82. doi:10.1080/10511970.2015.1053642

Kinley, (2016). Grade Twelve Students Establishing the Relationship Between Differentiation and Integration in Calculus Using graphs. IEJME-Mathematics Education, 11(9), 3371-3385.

Maharaj, A., \& Wagh, V. (2014). An outline of possible pre-course diagnostics for differential calculus. South African Journal of Science, 110(7/8), 1-7. doi:10.1590/sajs.2014/20130244

Meyers, C., \& Jones, T. B. (1993). Promoting active learning: Strategies for the college classroom. San Francisco, CA: Jossey-Bass.

National Research Council, \& Bass, H. (1993). Measuring what counts: Conceptual guide for mathematics assessment. Washington, DC: National Academy Press.

Porter, M. K., \& Masingila, J. O. (2000). Examining the effects of writing on conceptual and procedural knowledge in calculus. Educational Studies in Mathematics, 42(2), 165-177.

Pugalee, D. K. (2001). Writing, Mathematics, and Metacognition: Looking for Connections Through Students' Work in Mathematical Problem Solving. School Science and Mathematics, 101(5), 236-245. doi:10.1111/j.1949-8594.2001.tb18026.x

Robert, A., \& Speer, N. (2001). Research on the teaching and learning of calculus/elementary analysis. In D. Holton (Ed.), The Teaching and Learning of Mathematics at University Level: An ICMI Study (Vol. 7, pp. 283-299). Dordrecht \& Boston: Kluwer Academic Publishers.

Rybolt, W., \& Recck, G. (2012). Conceptual versus Computational Formulae in Calculus and Statistics Courses. The International Journal of Technology, Knowledge, and Society: Annual Review, \&(2), 1-6. doi:10.18848/1832-3669/cgp/v08i02/56287.

Scheja, M., \& Pettersson, K. (2009). Transformation and contextualization: conceptualizing students' conceptual understandings of threshold concepts in calculus. Higher Education, 59(2), 221241. doi:10.1007/s10734-009-9244-7

Thompson, P. W. (1994). Images of rate and operational understanding of the fundamental theorem of calculus. Educational Studies in Mathematics, 26(2-3), 229-274. doi:10.1007/bf01273664 
Vincent, B., LaRue, R., Sealey, V., \& Engelke, N. (2015). Calculus students' early concept images of tangent lines. International Journal of Mathematical Education in Science and Technology, 46(5), 641-657. doi:10.1080/0020739x.2015.1005700.

Yoder, J., \& Hochevar, C. (2005). Encouraging Active Learning Can Improve Students' Performance on Examinations. Teaching of Psychology, 32(2), 91-95. doi:10.1207/s15328023top3202_2 